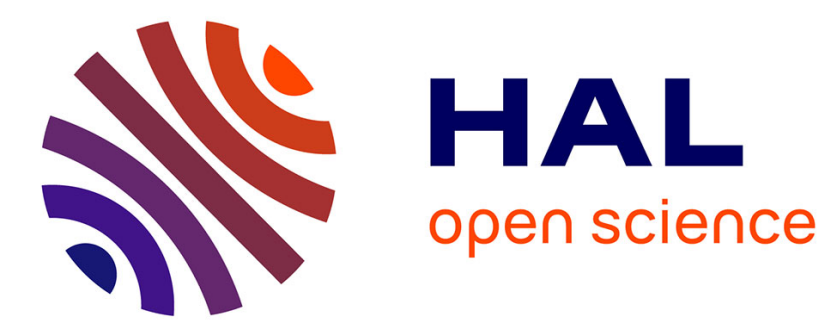

\title{
Study of an expert system on preservation of the quality of post-harvest grain: planning of storage technical route
} Amadou Ndiaye

\section{To cite this version:}

Amadou Ndiaye. Study of an expert system on preservation of the quality of post-harvest grain: planning of storage technical route. IFAC Proceedings Volumes, 1995, 28 (6), pp.85-93. 10.1016/S14746670(17)47165-5 . hal-01537761

\section{HAL Id: hal-01537761 \\ https://hal.science/hal-01537761}

Submitted on 12 Jun 2017

HAL is a multi-disciplinary open access archive for the deposit and dissemination of scientific research documents, whether they are published or not. The documents may come from teaching and research institutions in France or abroad, or from public or private research centers.
L'archive ouverte pluridisciplinaire HAL, est destinée au dépôt et à la diffusion de documents scientifiques de niveau recherche, publiés ou non, émanant des établissements d'enseignement et de recherche français ou étrangers, des laboratoires publics ou privés.

\section{다(1)(2)}

Distributed under a Creative Commons Attribution - ShareAlikel 4.0 International 


\title{
STUDY FOR AN EXPERT SYSTEM ON PRESERVATION OF THE QUALITY OF POST-HARVEST GRAIN : PLANNING OF STORAGE TECHNICAL ROUTE
}

\author{
A. Ndiaye \\ INRA - LIDS, Domaine de la Grande Ferrade, B.P. 81, 33883 Villenave d'Ornon Cedex, \\ France \\ Tel. : (33) 568432 94, Fax : (33) 568432 89, E-mail : amadou.ndiaye@bordeaux.inra.fr
}

\begin{abstract}
The planning space is represented on 3 different abstraction levels : grain, operation, and silo. The planning is hierarchical and non linear and involves several techniques of artificial intelligence : causal diagnosis of grain quality at grain level ; selection of the storage operations needed to preserve grain quality at operation level ; ordering the selected operations, allocating and reasoning on resources, at silo level.

The main originality of this study lies in the introduction of a preventive approach to stored grain management which is guided by the preservation of the grain quality.
\end{abstract}

Keywords : Expert system, Artificial intelligence, Hierarchical planning, Causal diagnosis, Qualitative reasoning, Reasoning on resources, Grain quality.

\section{INTRODUCTION}

Developing expert systems to help maintain the quality of stored grain is one of the major concerns of post-harvest research. Storage proves to be the weak link in foodstuff quality chain. Modern farming technics have allowed an increase in the world production of cereals ; and, consequently, an increase in storage capacities and duration. It so happens that any lengthening of storage duration means an increase in the risk of grain degradation. Grain is a living organism, and the normal outcome of its vital activity is germination and oxidation phenomena. A stock of grain is the natural environment of insects, mites, and micro organisms : insects and mites consume and spoil the grain (Fleurat-Lessard et al., 1994a), while micro-organisms deteriorate and contaminate it (Cahagnier et al., 1993).

Degradation in grain quality is a normal and irreversible process. Degradation speed depends on the environment factors : temperature, moisture, impurity rate and $\mathrm{CO}_{2}$ content. The question we are asking is the following : how to store grain in order to preserve its quality ? Of course one should start with a definition of the idea of grain quality.
Grain quality is a complex entity in which four different specific qualities take place (intrinsic \& physico-chemical, sanitary \& security, technological and nutritional).These specific qualities are in function with the environment factors and the degradation agents which are measurable data. The grain state of quality can be appreciated through grain quality tests. These tests are put together depending upon which qualities they can evaluate (Ndiaye and Fleurat-Lessard 1994)

The interest of using expert systems (ES) to take up this problem can be explained by 1) the lack of any grain quality preservation model ; 2) the strongly experimental and granulary nature of the available knowledge. For example, the population growth rates are known only for certain degradation agents, at certain temperatures and moisture and for certain grains (Beckett et al., 1994). During the last years, several pest control ES have been developed to help make decisions within the context of fight against degradation agents present in stored grain (GPA ; Wilkin, et al.1991), (SGA ; Flinn and Hagstrum, 1990), (PestMan ; Longstaff, 1993) (PEST ; Pasqual and Mansfield, 1988). These ES have confirmed the interest of ES to help preserve grain on one hand, and, on the other hand, have shown the limits of pest 
control as far as grain quality maintenance is concerned.

Our aim is to build a preventive system of stored grain quality maintenance guided by the measured values of the environment factors. The studies on environment factors show that they give an early information on the risks of quality degradation (Fleurat-Lessard et al., 1994b ; Wrigley et al. 1994 ; Juliano, 1994). Our approach differs from existing systems in that we give priority to the prevention of grain quality degradation, and therefore to predictive signs of degradation. The fight against degradation agents remains a mean to decontaminate grain.

Our strategy of preventive preservation of stored grain quality is based on a good appreciation of instantaneous grain quality in order to be able to determine the optimal storage technical route allowing us to monitor the quality of grain. It involves the following 4 stages : 1) to establish the state of grain quality before storage, 2) to determine an optimal storage preventive technical route, 3) to monitor the evolution of grain quality during storage, 4) to react to any event representing a foreseen or effective quality degradation and readjust the storage technical route accordingly.

This paper presents the different planning stages of the stored grain preventive maintenance : causal diagnosis of grain quality, selection of the operations needed for grain storage, and the ordering of these operations in storage preventive technical routes. These two stages constitute the phase of storage technical route planning.

\section{PLANNING OF STORAGE TECHNICAL ROUTE}

Within the planning space of the storage technical route, we distinguish 12 different entities (Table 1) which are linked by causality relations of a influence or give_information_on type (Steyer et al., 1993).

Table 1. Entities present in the space of the storage technical route planning

\begin{tabular}{|c|c|c|c|}
\hline Entity & Variable & Abbreviation & Type \\
\hline Available Resources & $\begin{array}{l}\text { Consumables } \\
\text { Equipments }\end{array}$ & $\begin{array}{l}\mathrm{Rc} \\
\mathrm{Re}\end{array}$ & Observation \\
\hline Degradation agents & $\begin{array}{l}\text { Presence of insects } \\
\text { Presence of mites } \\
\text { Proliferation of micro-organisms }\end{array}$ & $\begin{array}{l}\text { PIns } \\
\text { PMit } \\
\Pi \mu \mathrm{O}\end{array}$ & Measurement \\
\hline Degradation Risks & $\begin{array}{l}\text { Insects } \\
\text { Germination } \\
\text { Micro-organisms } \\
\text { Mites }\end{array}$ & $\begin{array}{l}\text { Ins } \\
\mathrm{G} \\
\mu \mathrm{O} \\
\mathrm{Mit}\end{array}$ & Calculation \\
\hline Environment factors & $\begin{array}{l}\text { Impurity rate } \\
\text { Moisture Content } \\
\text { Temperature } \\
\% \mathrm{CO} 2\end{array}$ & $\begin{array}{l}\operatorname{ImpR} \\
\mathrm{MC} \\
\theta \\
\mathrm{CO} 2\end{array}$ & Measurement \\
\hline Grain aspect & $\begin{array}{l}\text { Color } \\
\text { Smell }\end{array}$ & $\begin{array}{l}\text { Color } \\
\text { Smell }\end{array}$ & Observation \\
\hline Grain identity & $\begin{array}{l}\text { Harvest year } \\
\text { Production area } \\
\text { Variety }\end{array}$ & $\begin{array}{l}\mathrm{HY} \\
\mathrm{PA} \\
\mathrm{Va}\end{array}$ & Observation \\
\hline Grain Quality & Grain Quality & Q & Calculation \\
\hline Quality test & $\begin{array}{l}\text { Bread making quality } \\
\text { Enzymatic activity } \\
\text { Grain hardness } \\
\text { Germinative power } \\
\text { Heavy metals } \\
\text { Lipid quality } \\
\text { Mycotoxins } \\
\text { Nutritional value } \\
\text { Pesticide residues } \\
\text { Protein content } \\
\text { Protein quality } \\
\text { Radioactivity } \\
\text { Specific weight } \\
\text { Starch quality } \\
\text { Weight of } 1000 \text { grains }\end{array}$ & $\begin{array}{l}\text { BQ } \\
\text { EA } \\
\text { GH } \\
\text { GP } \\
\text { HM } \\
\text { LQ } \\
\text { MT } \\
\text { NV } \\
\text { PR } \\
\text { PC } \\
\text { PQ } \\
\text { Rad } \\
\text { SW } \\
\text { SQ } \\
\text { W1000 }\end{array}$ & Measurement \\
\hline
\end{tabular}




\begin{tabular}{llll} 
Specific Qualities & Intrinsic \& physico-chemical Quality & Qipc & Calculation \\
& Nutritional Quality & Qn & \\
& Sanitary \& security Quality & Qss & \\
& Technological Quality & Qt & \\
Storage operation & Possible storage Operation & O & Calculation \\
Storage Technical Route & Storage Technical Route & STR & Calculation \\
Utilisations of Grain & $\begin{array}{l}\text { grain possible destination } \\
\text { maximal length of storage }\end{array}$ & U & Calculation \\
& & $\Delta t$ & \\
\hline
\end{tabular}

These entities are gathered in 3 different knowledge levels (Fig. 1):

- The grain level is the level of grain quality diagnosis. The quality of grain is appreciated from the environment factors, presence or proliferation of degradation agents, quality tests, grain identity and aspect.
- The operation level is the level of selection of storage operations. The operations are selected on the basis of risks of grain degradation, and possible utilisation of the grain.

- The silo level is the level of the setting up of the Storage Technical Routes (STR). The STR are made of storage operations which can be executed in the silo.

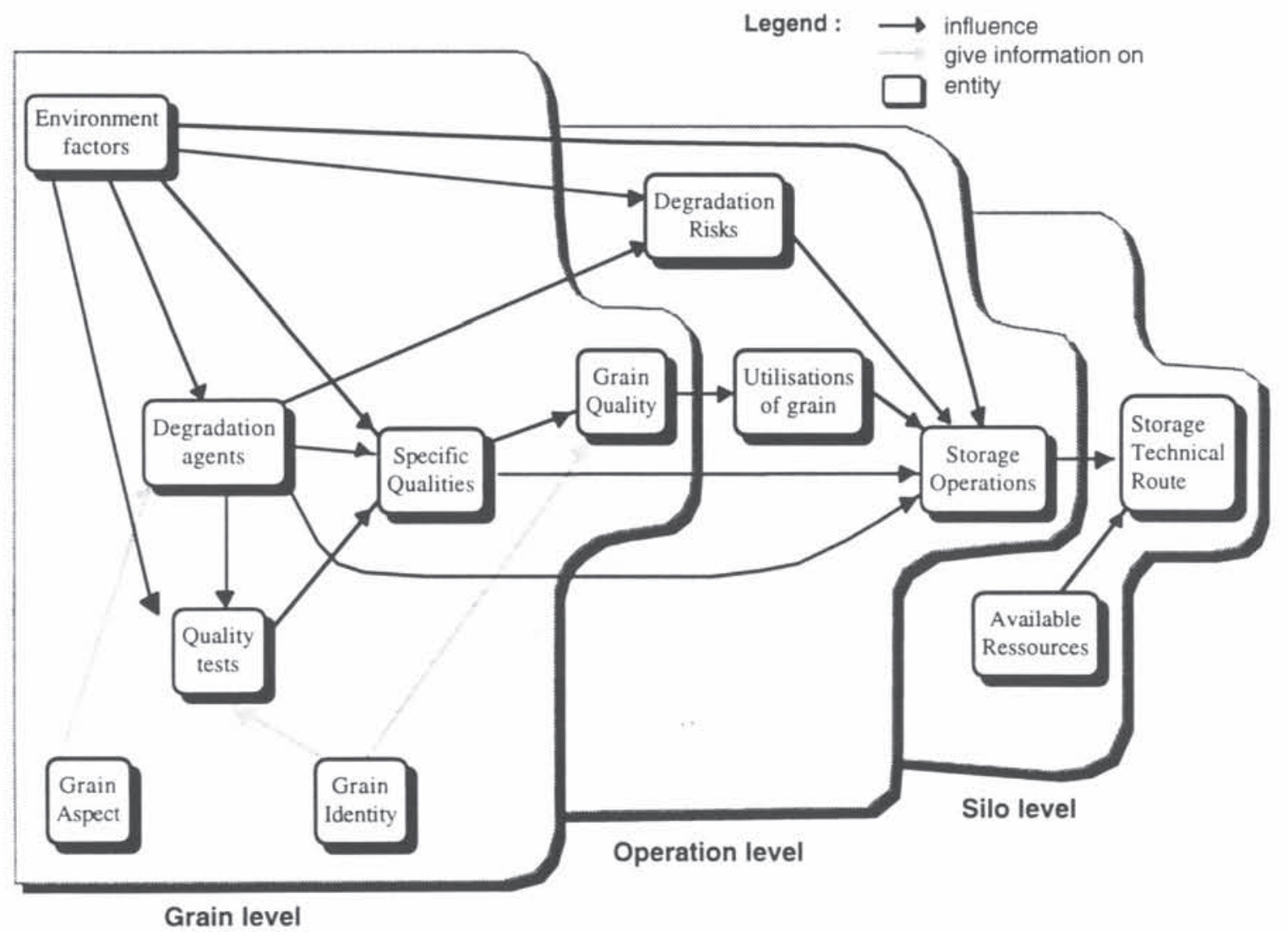

Fig. 1. The relations between the entities present in the space of the storage technical route

The planning is hierarchical and non linear : the grain quality is appreciated at grain level, the operations of quality preservation are selected at operation level, and the ordering of operations in storage technical routes is made at silo level. Each of these knowledge levels is an abstraction level of the cognitive process of determination of a storage technical route. (Fig. 2) 


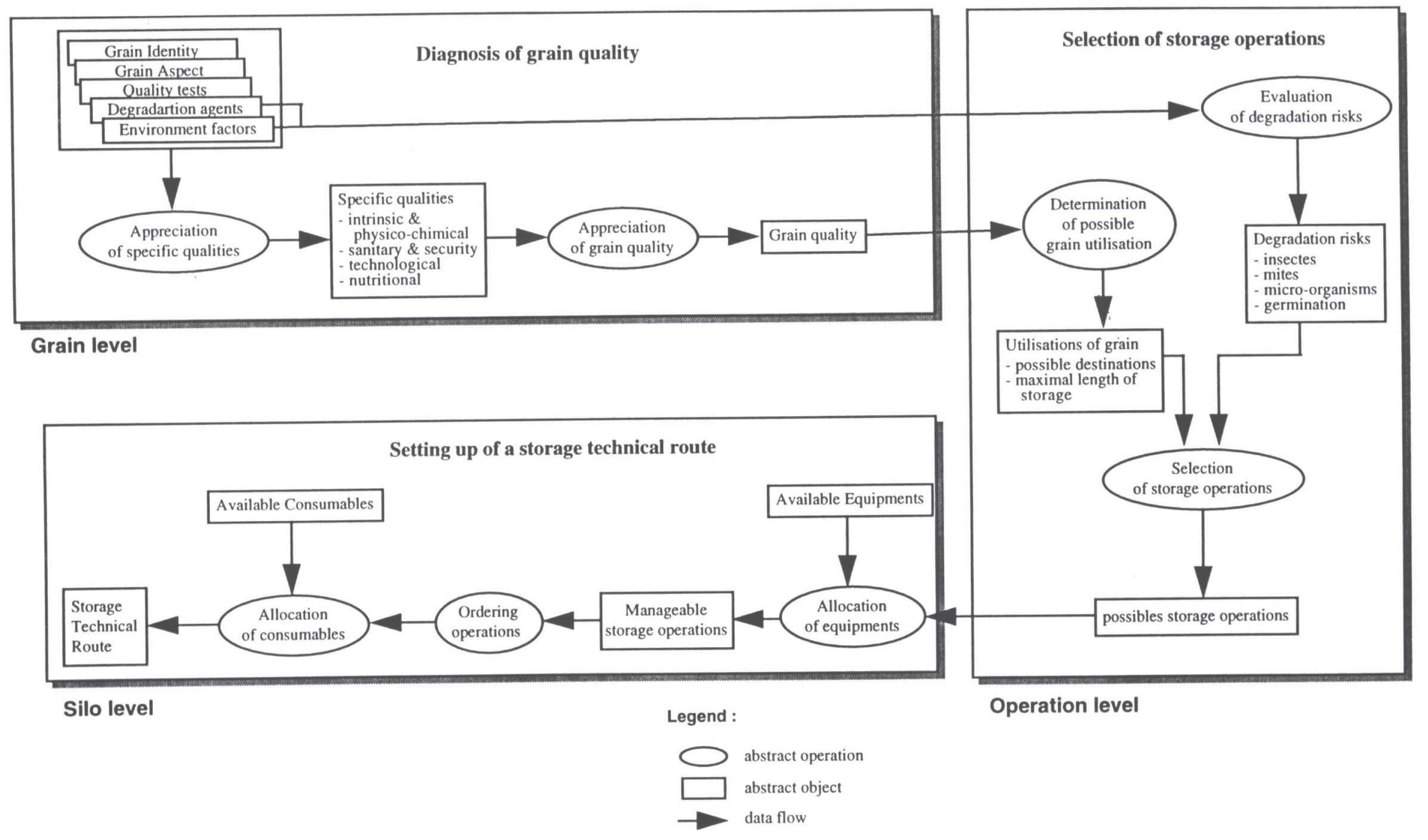

Fig. 2. The process of the planning of storage technical route 


\section{1. diagnosis of grain quality}

In literature, grain quality is defined nowadays in function with the grain foreseen utilisation: "the word 'quality' means suitability for the specific process or utilisation for which it's destined" (Wrigley et al., 1994). Such a definition infers an inversion in causality between quality and future utilisation of grain. Each utilisation implies a given quality of grain. This required quality must be available at the time of utilisation to make it possible. Aiming at preservation of grain quality during storage on one part, and at assigning it to an economically optimal utilisation on another part, it is necessary to respect the causality direction : from quality to grain utilisation. Therefore it is imperative to determine the quality in function with the characteristics and not in function with the foreseen utilisation of the grain which is, after all, only a bet on future.

It is still difficult nowadays to give a formal definition of grain quality, so we will limit ourselves to the following operating definition : grain quality comes out of its specific qualities: intrinsic \& physico-chemical, sanitary \& security, nutritional and technological.

We determine the quality of grain through a process of causal diagnosis, the data of which are : the environment factors, the degradation agents, the quality tests and the identity of grain. On the basis of these measurements or observations which are not necessarily all known, we appreciate the specific qualities of grain ; and on the basis of these specific qualities, we appreciate the quality of grain.

At grain level the data and the appreciations are reduced to quantitative values. the formalism for qualitative reasoning developed by Guerrin (1991) in the domain of ecology gives us a sufficient framework for grain quality diagnosis. Our quantity space (QS) needs seven symbols (vvl, vl, l, m, h, vh, vvh) (Table 2)

Table 2. Quantity space symbols and some interpretations

\begin{tabular}{ccccccc}
\hline vvl & vl & l & m & h & vh & vvh \\
\hline very very bad & very bad & bad & average & good & very good excellent \\
very very low & $\begin{array}{c}\text { very low } \\
\text { very damp }\end{array}$ & low & damp & & high & very high very very high \\
& & & dry & very dry \\
\hline
\end{tabular}

This formalism devised to interpret heterogeneous data, allows us to :

- Express the grain heterogeneous characteristics into homogeneous qualitative valuation.

Example : a moisture content (MC) between 13 and $14 \%$ is considered average, and a

Example : valuation table of the intrinsic \& physico-chemical quality (Qipc) of wheat from grain specific weight (SW) and moisture content (MC) and impurity rate (ImpR) :

SW \begin{tabular}{c|c:c:c:c:c}
$\mathbf{X}$ & $\mathrm{vl}$ & $\mathrm{l}$ & $\mathrm{m}$ & $\mathrm{h}$ & $\mathrm{vh}$ \\
\hline $\mathrm{l}$ & $\mathrm{vvl}$ & $\mathrm{l}$ & $\mathrm{vl}$ & $\mathrm{vl}$ & $\mathrm{vl}$ \\
\hdashline $\mathrm{m}$ & $\mathrm{vvl}$ & $\mathrm{m}$ & $\mathrm{m}$ & $\mathrm{m}$ & $\mathrm{l}$ \\
\hdashline $\mathrm{h}$ & $\mathrm{vvl}$ & $\mathrm{vh}$ & $\mathrm{h}$ & $\mathrm{h}$ & $\mathrm{m}$ \\
\hline
\end{tabular}

specific weight (SW) over $76 \mathrm{~kg} / \mathrm{hl}$ is considered high; and therefore MC and SW will have as respective values $m$ and $l$.

- Convey the experience of the human experts through qualitative calculation rules and tables.
- Represent the causal dependencies between variables representative of the grain quality domain under the form of an oriented graph called causal graph (Fig. 3) : the nodes represent the variables, the arcs in full line represent the influence relations (cause /effect) and the arcs in streaked line represent the give_information_on relations.

\begin{tabular}{c|c:c:c:c:c:c} 
Qipc & vvl & $v l$ & 1 & $\mathrm{~m}$ & $\mathrm{~h}$ & $\mathrm{vh}$ \\
\hline $\mathrm{l}$ & $\mathrm{vvl}$ & $\mathrm{vl}$ & $\mathrm{l}$ & $\mathrm{l}$ & $\mathrm{l}$ & 1 \\
\hdashline ImpR $\mathrm{m}$ & $\mathrm{vvl}$ & $\mathrm{vl}$ & $\mathrm{l}$ & $\mathrm{m}$ & $\mathrm{h}$ & $\mathrm{vh}$ \\
\hdashline $\mathrm{h}$ & $\mathrm{vvl}$ & $\mathrm{vl}$ & $\mathrm{l}$ & $\mathrm{h}$ & $\mathrm{h}$ & $\mathrm{vvh}$ \\
\hline
\end{tabular}

\section{Examples :}

1- baking wheat with a moisture content (MC) above $15 \%$ will be of an average or bad intrinsic \& physico-chemical quality (Qipc) except if it benefits from a high specific weight (above $76 \mathrm{~kg} / \mathrm{hl}$ ). Moisture content is a cause for bad intrinsic \& physico-chemical 
quality, which is expressed by the influence relation MC $\rightarrow$ Qipc

2- wheat of Soissons variety (Va) harvested anywhere in France (PA) in 1994 (HY) belongs to the category superior baking wheat averaging a W of 222 and a $\mathrm{P} / \mathrm{L}$ of 0,67 (for bread making quality), a protein content (PC) of $11,1 \%$, a $\mathrm{Med}$-hard P.S.I. grain hardness (GH) and a Hagberg of 344 seconds (for enzymatic activity). The information on cereal quality is given each year after a "Cereal Quality" survey made by ONIC and ITCF" in every French production area and on all varieties with a significant tonnage. The results of this survey are available as early as October for July/August harvests. A prediction of cereal quality covers the period from harvest time to the publication of the results of the survey. This example illustrates the give_information_on relation linking the variables Va, PA and HY (grain identity) to each of the following variables: $\mathrm{Q}, \mathrm{W}, \mathrm{P} / \mathrm{L}$, PC, GH, Hagberg.

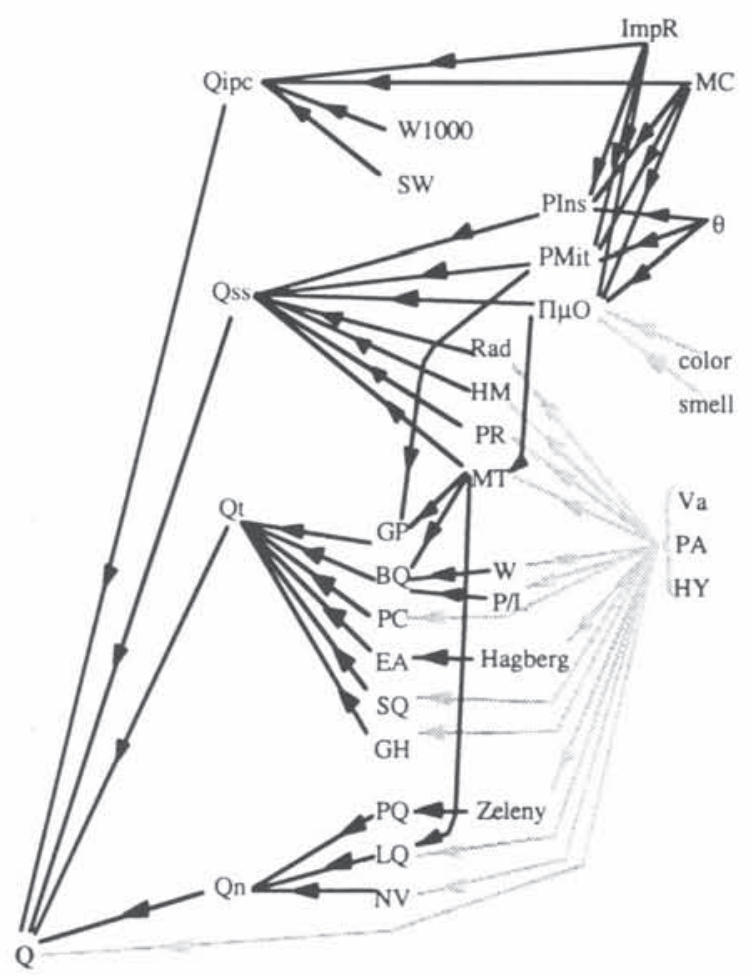

Fig. 3. Causal graph of variables present at grain level

At grain level we can distinguish five types of data :

- the data which are immediately available for a first appreciation of grain quality : $\theta, \mathrm{MC}, \mathrm{ImpR}, \mathrm{SW}$, PIns, color, smell, Va, PA, HY. These data, which

* ONIC : Office National Interprofessionnel des Céréales ITCF : Institut Technique des Céréales et Fourrages are systematically measured or observed in all storing organisms, are sufficient for a first appreciation of quality. The grain identity (Va, PA, HY) is used to obtain the average values of the quality tests and the knowledge on the security which is specific to the variety, the harvest year, and the grain production area. The average values of the quality tests are used to appreciate the technological and nutritional qualities (Qt) and (Qn) ; and the knowledge on grain security is exploited to have good indications on the safety aspects of the sanitary \& security quality (Qss). The production area exposure to radioactivity at a given period is an example of the knowledge on grain security. The color and smell data are sensorial indicators of micro-organism proliferation.

- the data indicating that additional tests should be carried out : PMit, П $\mu \mathrm{O}, \mathrm{MT}, \mathrm{PR}, \mathrm{HM}$. Presence of mites (PMit), in particular Acarus siro, implies checking the germinative power (GP). Proliferation of micro-organisms $(\Pi \mu \mathrm{O})$ implies an ergosterol measuring out to precise the levels of degradation and contamination by grain mycotoxins. The presence of mycotoxins (MT) implies an investigation on types and species, and eventually checking the bread making quality (BQ), the germinative power (GP) and the lipid quality (LQ). The presence of pesticide residues (PR) implies a measuring out of the active residues in order to improve the proportion of any pesticide application and to determine a minimal grain storage duration in relation with the residues activity period. The presence of heavy metals (HM) implies a measuring out of $\mathrm{Pb}$ and $\mathrm{Cd}$.

- the data for fast confirmation of the quality obtained during the first appreciation : PC, GP, GH, PQ. These tests which can be done rather quickly (within a 24 hour delay) will complement the available data for a better valuation of the technological and nutritional qualities (Qt) and (Qn) and therefore of the grain quality.

- the data indicating a redhibitory defect at grain quality level : Rad, MT. Radioactive grain is not edible. Cancer-producing mycotoxins (MT) such as aflatoxin $B 1$ have a tolerance threshold in the region of $\mathrm{ppb}$; which in fact means that their presence in grain cannot be tolerated.

- data on additional information to honor a specific schedule of conditions : W1000, П $\mu$ O, MT, PR, HM, Rad, BQ, EA, SQ, LQ, NV. For example the nutritional value (NV) will be measured only on grain intended for controlled food such as baby food or diets for sick people.

Our strategy to diagnose the grain quality is progressive and data driven. It can be split up into five stages :

1) To make a first causal diagnosis of grain quality from the data that are immediately available. 
2) To identify the necessary additional tests from the data indicating additional tests to be carried out.

3) To check that there is no redhibitory defect from the data indicating redhibitory defects.

4) To confirm grain quality from the data of fast confirmation of quality.

5) If necessary, to confirm grain quality from the additional information data.

\subsection{Selection of storage operations}

We can distinguish nine different storage operations :

- Airtight storage : storage of grain under modified or confined atmosphere.

- Apply pesticides : application of any pesticide by : nebulisation, spraying or fumigation.

- Clean : any grain cleaning operation due to high impurity rate.

- Cool : cooling down ventilation or refrigeration of grain.

- Dry : drying of grain with heat supply.

- Mix : mixing grains of equivalent quality in order to improve their respective specific qualities Qipc or Qss

- Move : any mechanical turn over operation of grain.
- Select bin : selection of the most adapted bin for preservation of grain quality. In the selection of the bin comes the fact that it can be filled with grains from different origins, but of same quality. - Stabilize : stabilization of grain with use of organic acid.

The role of each of these operations is to bring an answer to a specific need for improvement or preservation of grain quality and for fight or prevention against degradation agents (Table 3)

\section{Examples :}

1- to cool the grain favours good preservation of its quality and prevents degradations due to insects and mites. The rate of isomultiplication of insects and mites decreases in proportion with temperature, and the sprouting and oxidation processes slow down. The combination of these phenomenon allows an increase in the period of grain preservation (Lasseran and Fleurat-Lessard, 1991, 1994).

2- to mix a very damp wheat with a very dry wheat of equivalent specific weight improves the intrinsic \& physico-chemical quality (Qipc) of grain and reduces the risk of degradation due to micro-organisms $(\Pi \mu \mathrm{O})$. The resulting grain will have a larger specific weight and damp, average or dry moisture content according to the proportions of the mixture .

\section{Table 3. storage operations}

\begin{tabular}{llll}
\hline Storage operations & Incidence on quality & $\begin{array}{l}\text { Effects on degradation } \\
\text { agents }\end{array}$ & Selection criteria \\
\hline Airtight storage & preservation & prevention & Ins, Mit, $\mu \mathrm{O}, \mathrm{U}, \Delta \mathrm{t}$ \\
Apply pesticides & preservation & fight, prevention & Ins, Mit, PIns, PMit, U, $\Delta \mathrm{t}$ \\
Clean & preservation & fight, prevention & Qipc, ImpR \\
Cool & preservation & prevention & Qipc, Ins, Mit, U, $\Delta t$ \\
Dry & improvement & prevention, fight & $\mu \mathrm{O}, \mathrm{Mit}, \mathrm{MC}, \Pi \mu \mathrm{O}$ \\
Mix & improvement & prevention & Qipc, Qss, MC, SW, HM, MT \\
Move & improvement & prevention, fight & $\mu \mathrm{O}, \mathrm{Mit}, \mathrm{MC}, \mathrm{PMit}, \Pi \mu \mathrm{O}$ \\
Select bin & preservation & prevention & $\mathrm{U}, \Delta \mathrm{t}$ \\
Stabilize & preservation & prevention & $\mu \mathrm{O}, \mathrm{U}, \Delta \mathrm{t}$ \\
\hline
\end{tabular}

We select the storage operations mainly in function with specific qualities (Qipc, Qss), degradation risks (Ins, Mit, $\mu \mathrm{O}$ ) and the foreseen utilisation of grain ( $\mathrm{U}$, $\Delta t$ ). These main criteria are backed up by the secondary criteria which are the environment factors (ImpR, MC, SW) and the degradation agents (PIns, PMit, $\Pi \mu \mathrm{O}$ ). Our selection mechanism is causal, it is guided by the cause/effect relation linking the main criteria to the secondary criteria. It can be expressed by a rule of this type :
If grain specific quality (Qipc) is very bad and the $\mathrm{MC}$ is very damp and the SW is average or high, then you have to Mix grain with grain of equivalent quality but with $d r y$ or very $d r y \mathrm{MC}$ and high SW.

Such a mixture will bring Qipc to good and $\mathrm{MC}$ to average or damp and SW to high.

We have just seen an example where the choice was made by selecting a storage operation. In the 
selection process we can also be led to exclude the selection of a storage operation. For example, if the corn is intended for human consumption, stabilization with an organic acid is excluded (it would leave a disagreeable taste).

\subsection{Setting up of a storage technical route}

A storage technical route is a succession of storage operations that should be undertaken in order to preserve grain quality. A storage operation is manageable only if it has been allocated the resources (equipment and consumables) necessary to its accomplishment. An equipment is a fitting such as : dryer, cooling aeration system, airtight storage system, etc.... A consumable is a pesticide or stabilizing product. The resources that are taken in account are the resources available at the storage silo.

Our strategy to set-up a technical route is as follows:

1) to allocate to each storage operation the equipment necessary to carry it out;

2) to order the manageable storage operations thus obtained in a plan ;

3) to allocate to each operation of this plan the products that are best adapted to its execution within the plan.

\subsubsection{Allocation of equipment}

The problem involved in the allocation of an equipment to a storage operation is the problem of checking whether the equipment exists, is available and is specifically adapted to the operation that should be carried out. For example, if you want to dry corn, you will first check if there is a dryer in the silo, then if it is available, and, last, if it is adapted to corn drying. Such an approach is easy to formalize in terms of preconditions to allocation rules (Wilkins, 1988).

\subsubsection{Ordering of manageable storage operations}

A manageable storage operation is caracterized by its process, its effects on grain, and the energy it consumes.

\section{Examples :}

1- To clean grain, you have to move it to the cleaning machine and to move it to the storage bin or to be weighed.

2- The Dry operation uses a dryer and its effects on grain are a decrease in grain moisture and an increase of its temperature.

3- The Cool operation uses a bin equipped with a cooling aeration or refrigeration system, and its effect on grain is a noticeable decrease of its temperature.
The example 1 shows that there exists a teleological relation (Sacerdoti, 1979) between Move and Clean. This teleological relation is due to the process of Clean. It also links Move to Apply pesticide, Mix and Stabilize. It implies that each of these operations is usually a double operation, except in some very precise cases. For example, Apply pesticide by fumigation does not need Move.

With examples 2 and 3 we can see that if you apply to grain a Cool operation followed by a Dry operation, the effects of the second operation would annul the effects of the first one. Therefore Dry should always precede Cool. The relation linking these two operations is a relation of order, determined by their effects on grain.

If we consider the operations Dry and $\mathrm{Cool}$, one can precede the other and inversely. No relation of order links these two operations. They can be considered as equivalent as regard the order, and therefore linked by a relation of equivalence.

We set up the order of the storage operations by using the 3 relations, teleological, of order and of equivalence ; and by taking into account the fact that some equipments use a great amount of electricity. There are usually hours in the day during which the electricity costs less (off-peak periods). Operations such as Dry which use up a lot of electricity can be preferably carried out during the off-peak periods. This constraint due to optimisation of storage cost influences the order of the operations.

\subsubsection{Allocation of the consumables}

Consumable resources are products and therefore can be shared and still considered as available. The problem involved in the allocation of consumables is selecting the product which is the most adapted to the storage operation process, to the equipment to be used, to the quality of grain and eventually to the concerned degradation agents.

\section{CONCLUSION}

The development of expert systems for stored grain management is a very young field of research (around 10 years). These last five years have been marked by the coming of pest control systems guided by the fight against insects and mites already present in the stored grain. These systems proved themselves to be little efficient for grain quality preservation.

Preserving the quality of stored grain is a new approach to stored grain maintenance implying the planning of the storage technical route. The data present in the planning space are heterogeneous. The planning process can be broken down into three stages : diagnosis of quality, selection of the storage 
operations and ordering of the operations. We approach them respectively through a causal qualitative reasoning, inference rules, and a reasoning on resources.

This first approach, which is sufficient to build a specific system, has to be developed in order to achieve a planning model of the storage technical route. One of our main difficulties to-date lies in the existence of significant areas in the field of stored grain maintenance for which knowledge is lacking.

\section{ACKNOWLEDGEMENTS}

The experts on grain quality preservation who took part in this study are : Francis FLEURAT-LESSARD and Bernard CAHAGNIER.

Part of this project has been financially supported by the CONSEIL REGIONAL D'AQUITAINE.

\section{REFERENCES}

BECKETT S.J., LONGSTAFF B.C., EVANS D.E., (1994). A comparison of the demography of four major stored grain coleopteran pest species and its implications for pest management. Proceedings 6th Int. Working Conf. Stored Product Protection, Canberra, April 94, 1, 4991-497. CAB International, Wallingford.

CAHAGNIER B., LESAGE B., RICHARDMOLARD D., (1993). Mould growth and conidiation in cereal grains as affected by water activity and temperature. Letters in Applied Microbiology, 17, 7-13.

FLEURAT-LESSARD F., ANDRIEU A.J., WILKIN D.R., (1994a). New trends in stored-grain infestation detection inside storage bins for permanent infestation risk monitoring. Proceedings 6th Int. Working Conf. Stored Product Protection, Canberra, April 94, 1, 397 402. CAB International, Wallingford.

FLEURAT-LESSARD F., JUST D., BARRIEU P., LE TORC'H J.M., RAYMOND P., SAGLIO P., (1994b). Effect of modified atmosphere storage on wheat seed germination vigour and on physiological criteria of the ageing process. Proceedings 6th Int. Working Conf. Stored Product Protection, Canberra, April 94, 2, 695 700. CAB International, Wallingford.

FLINN P.W., HAGSTRUM D.W., (1990). Stored Grain Advisor : a knowledge-based system for management of insect pests of stored grain. $A I$ Applications, 4, 44-52.

GUERRIN F., (1991). Qualitative reasoning about an ecological process : interpretation in Hydroecology. Ecological Modelling, 59, 165 201.
JULIANO B.O., (1994). Concern for quality maintenance during storage of cereals and cereal products. Proceedings 6th Int. Working Conf. Stored Product Protection, Canberra, April 94, 2, 663-665. CAB International, Wallingford.

LASSERAN J.C., FLEURAT-LESSARD F., (1991). Aeration of grain with ambient or artificially cooled air : a technique to control weevils in temperate climates. Proceedings 5th Int. Working Conf. Stored Product Protection, Bordeaux, Sept. 90, 2, Fleurat-Lessard \& Ducom Ed., 1221-1231.

LASSERAN J.C., FLEURAT-LESSARD F., (1994). Quality enhancement of stored grain by improved design and management of aeration. Proceedings 6th Int. Working Conf. Stored Product Protection, Canberra, April 94, 1, 296299. CAB International, Wallingford.

LONGSTAFF B.C., (1993). Expert System for Managing Grain Pests in Store. Postharvest News and Informations, 4, 117N.

NDIAYE A., FLEURAT-LESSARD F., (1994). Research on an expert system for appropriate management of the quality of stored grain for food and feed processing. Proceedings 94 Int. symp. and exhib. on quality of foodstuffs from cereal grains and oil seeds. Beijing, Nov. 94, Xie Guifang \& Ma Zhongdeng. Ed.,537-540.

PASQUAL G.M., MANSFIELD J., (1988). Development of a Prototype Expert System for Identification and Control of Insect Pests. Computers and Electronics in Agriculture, 2, 263-276.

SACERDOTI E.D. (1979). Problem solving tactics. Proceedings Int. Joint Conf. on Artificial Intelligence, Tokyo, 79, 1077-1085.

STEYER J.P., QUEINNEC I., POURCIEL J.B., GOMA G., (1993). On the interest of a qualitative approach in biotechnological process modeling and control. Procedings Artificial Intelligence for Agriculture and Food, Nîmes, Oct. 93, 221-230.

WILKIN D.R., MUMFORD J.D., NORTON G., (1991). The role of expert systems in current and future grain protection. Proceedings 5th Int. Working Conf. Stored Product Protection, Bordeaux, Sept. 90, 3, Fleurat-Lessard \& Ducom Ed., 2039-3046.

WILKINS D.E. (1988). Practical planning : extending the classical AI planning paradigm. Morgan Kaufmann.

WRIGLEY C.W., GRAS P;W., BASON M.L., (1994). Maintenance of grain quality during storage - prediction of the conditions and period of 'safe' storage. Proceedings 6th Int. Working Conf. Stored Product Protection, Canberra, April 94, 2, 666-670. CAB International, Wallingford. 